\title{
Effectiveness of Swirski-mite (Amblyseius swirskii Athias-Henriot) in control of two-spotted spider mite (Tetranychus urticae Koch) on cucumber plants treated with biostimulants
}

\author{
Efektywność dobroczynka Swirski (Amblyseius swirskii Athias-Henriot) \\ w ograniczaniu liczebności przędziorka chmielowca (Tetranychus urticae \\ Koch) na roślinach ogórka traktowanych biostymulatorami
}

\author{
Anna Tomczyk*, Paulina Andryka
}

\begin{abstract}
Summary
The experiments were conducted, on cucumber plants cultivar Aramis, treated and not treated with the biostimulants: Asahi SL and Siapton $10 \mathrm{~L}$, in the glasshouse and laboratory conditions. The aim of the study was to evaluate if the application of biostimulants in cucumber cultivation can influence the efficacy of biological control of Tetranychus urticae by predatory mite Amblyseius swirskii Athias-Henriot. It was found that $A$. swirskii decreased development of $T$. urticae population on both treated and not treated plants with biostimulants. The effectiveness of $A$. swirskii, at the low infestation of spider mites, was similar on the plants cultivated without biostimulants and the plants treated with Asahi SL while lower on the plants treated with Siapton $10 \mathrm{~L}$. A similar dependence was also observed for the development of predator population on these plants. The highest predator population developed on plants severely infested by spider mites and treated with Asahi SL. With large number of mites on leaves the biostimulant increased also effectiveness of predator, which occurred as high consumption of $T$. urticae eggs and young larvae.
\end{abstract}

Key words: cucumber; Tetranychus urticae; biostimulants; Amblyseius swirskii

\section{Streszczenie}

Doświadczenia były prowadzone w warunkach szklarniowych i laboratoryjnych na roślinach ogórka odmiany Aramis, traktowanych i nietraktowanych biostymulatorami: Asahi SL i Siapton 10 L. Celem badań było określenie czy zastosowanie biostymulatorów w uprawie ogórka szklarniowego może wpłynąć na skuteczność biologicznego zwalczania Tetranychus urticae za pomocą drapieżnego roztocza Amblyseius swirskii. Wykazano, że A. swirskii ograniczał rozwój populacji $T$. urticae zarówno na roślinach traktowanych, jak i nietraktowanych biostymulatorami. Skuteczność $A$. swirskii, w przypadku słabego porażenia przez przędziorki była podobna na roślinach uprawianych bez biostymulatorów i na roślinach traktowanych preparatem Asahi SL, niższa natomiast po zastosowaniu preparatu Siapton 10 L. Podobną zależność obserwowano także w przypadku rozwoju populacji drapieżcy na tych roślinach. Największa populacja drapieżcy rozwijała się na silnie porażonych przez przędziorki roślinach, traktowanych preparatem Asahi SL. Przy dużej liczbie szkodnika na liściach, biostymulator ten zwiększał także efektywność drapieżcy, przejawiającą się wysoką konsumpcją jaj i młodych larw T. urticae.

Słowa kluczowe: ogórek; Tetranychus urticae; biostymulatory; Amblyseius swirskil

\footnotetext{
Szkoła Główna Gospodarstwa Wiejskiego w Warszawie

Samodzielny Zakład Entomologii Stosowanej

Nowoursynowska 159, 02-776 Warszawa

*corresponding author: anna_tomczyk@sggw.pl
} 


\section{Wstęp / Introduction}

Dobroczynek Swirskii (Amblyseius swirskii A.-H.) jest wielożernym drapieżnym roztoczem $\mathrm{z}$ rodziny dobroczynkowatych (Phytoseiidae). Pochodzi ze wschodniego regionu śródziemnomorskiego - Włoch, Izraela, Cypru i Egiptu. W niektórych publikacjach pojawia się pod nazwą Typhlodromips swirskii.

Od 2005 roku jest wprowadzany lub testowany w różnych krajach Europy, Afryki Północnej, Ameryki Północnej, a także w Azji do zwalczania drobnych stawonogów, zarówno w warunkach naturalnych, jak i szklarniowych. W Polsce jest stosowany od 2007 roku do biologicznego zwalczania szkodników w uprawach warzyw i roślin ozdobnych w szklarni. Wykazano jego skuteczność w zwalczaniu wciornastka zachodniego (Frankliniella occidentalis Pergande), mączlika szklarniowego (Trialeurodes vaporariorum Westw.), a także przędziorka chmielowca (Tetranychus urticae Koch) (Górski 2008; Fiedler 2010).

Skuteczność drapieżnych roztoczy w ograniczaniu liczebności populacji szkodników zależy od szeregu czynników, zarówno abiotycznych, jak i biotycznych, tj. od temperatury, wilgotności, ale także od gatunku szkodnika i rośliny na którą jest wprowadzany (Heintz i wsp. 2004; Onzo i wsp. 2012). Na zachowanie i efektywność drapieżcy mają także wpływ odmianowe cechy roślin oraz ich stan fizjologiczny (Cortesero i wsp. 2000; Onzo i wsp. 2012; Buitenhuis i wsp. 2014). Duże znaczenie może mieć sposób nawożenia czy stosowanie substancji o charakterze induktorów odporności lub biostymulatorów, gdyż mogą one wpływać na zawartość pierwotnych i wtórnych metabolitów roślinnych, ważnych zarówno dla szkodnika, jak i drapieżcy (Cortesero i wsp. 2000; Gawrońska i Przybysz 2011; Buitenhuis i wsp. 2014). Mimo, że przędziorek chmielowiec jest gatunkiem polifagicznym, jakość rośliny żywicielskiej jest jednym z najważniejszych czynników wpływających na rozwój jego populacji (Tomczyk 1989). Liczebność szkodnika na roślinie ma bezpośredni związek ze skutecznością jego wrogów naturalnych. Badania Dicke i wsp. (1999) wykazały, że rośliny uszkodzone przez przędziorki wydzielają lotne substancje, które informują drapieżcę o obecności szkodnika, a potraktowanie roślin induktorami odporności nasila wydzielanie tych związków i zwiększa aktywność drapieżcy.

Celem badań było określenie, czy zastosowanie wybranych biostymulantów roślin w uprawie ogórka, zaatakowanej przez przędziorka chmielowca może zmieniać efektywność biologicznego zwalczania tego szkodnika za pomocą dobroczynka Swirskii.

\section{Porównywano:}

1. Rozwój populacji Tetranychus urticae na roślinach traktowanych i nietraktowanych biostymulatorami Asahi SL i Siapton $10 \mathrm{~L}$, przed i 2 tygodnie po wprowadzeniu drapieżnego roztocza $A$. swirskii.

2. Rozwój populacji drapieżcy na roślinach traktowanych i nietraktowanych biostymulatorami w przypadku niskiego zagęszczenia populacji szkodnika na liściach.

3. Rozwój populacji $A$. swirskii na liściach roślin z wysoką liczebnie populacją szkodnika, zapewniającą dostatek pokarmu.
4. Efektywność drapieżcy w ograniczaniu liczby jaj i larw T. urticae (konsumpcja) na liściach roślin traktowanych i nietraktowanych biostymulatorami.

\section{Materiały i metody / Materials and methods}

Badania prowadzono w warunkach szklarniowych i laboratoryjnych, na roślinach ogórka odmiany Aramis, traktowanych i nietraktowanym biostymulatorami: Asahi SL (mieszanina o-nitrofenolanu sodu i 5-nitroguaiaklanu sodu) i Siapton 10 L (mieszanina aminokwasów i oligopeptydów). Sadzonki roślin podzielono na 3 grupy, przeznaczone do różnych zabiegów: kontrolna - bez biostymulatorów (rośliny opryskiwane wodą), rośliny do opryskiwania preparatem Asahi SL i rośliny do opryskiwania preparatem Siapton 10 L. Zabiegi wykonano dwukrotnie w czasie trwania doświadczenia, przy użyciu opryskiwacza ręcznego o pojemności $2 \mathrm{dcm}^{3}$, w fazie $2-3$ liści, tuż po posadzeniu roślin na stałe miejsce w szklarni oraz dwa tygodnie później. Preparat Asahi SL stosowano w stężeniu $0,1 \%$, a Siapton $10 \mathrm{~L} \mathrm{w}$ stężeniu $0,25 \%$. Każdą grupę roślin umieszczono na oddzielnym parapecie $\mathrm{w}$ komorze szklarniowej. Rośliny wysadzono do ustawionych na parapetach pierścieni wypełnionych substratem ogrodniczym.

Przeprowadzono dwa doświadczenia szklarniowe i jedno laboratoryjne. W pierwszym doświadczeniu użyto 14 roślin, a w drugim 10, w każdej badanej grupie.

\section{Doświadczenie I}

Dwa dni po wysadzeniu roślin do pierścieni wprowadzono na nie po 15 samic przędziorka chmielowca (5 samic na jeden liść). Po 4 tygodniach żerowania szkodnika określano jego liczebność na losowo wybranym jednym liściu ze środkowej części każdej rośliny, z wszystkich grup doświadczalnych. Następnie na uszkodzone przez przędziorki liście wprowadzono drapieżnego roztocza - A. swirskii w liczbie 10 osobników. Po dwóch tygodniach od momentu wprowadzenia drapieżcy liczono ruchome stadia ofiary (T. urticae) i drapieżcy (A. swirskii).

\section{Doświadczenie II}

Rośliny wysadzano w szklarni, opryskiwano preparatami i porażano przędziorkami podobnie, jak w doświadczeniu I. Po 5 tygodniach żerowania szkodnika, kiedy dolne liście roślin były już silnie uszkodzone, policzono ruchome stadia rozwojowe przędziorka chmielowca na 8 kolejnych, dolnych liściach roślin, w każdym wariancie doświadczalnym i wprowadzono na nie po 2 osobniki A. swirskii. Po 3 tygodniach określono na każdej roślinie liczbę osobników $A$. swirskii na liściach, na których drapieżca był wprowadzony oraz na 5 młodych liściach (wierzchołkowych).

\section{Doświadczenie laboratoryjne}

W warunkach laboratoryjnych określano intensywność żerowania drapieżcy stosując jako pokarm jaja i młode stadia rozwojowe przędziorka chmielowca, na młodych (w stadium 3 liści) roślinach ogórka, traktowanych i nietraktowanych biostymulatorami. Rośliny uprawiano w do- 
niczkach, w komorze wzrostowej oświetlanej światłem jarzeniowym - długość dnia 15 godzin. Użyto po 12 roślin na każdy wariant doświadczalny.

Trzy dni po opryskaniu roślin wodą lub biostymulatorami, na środkowy liść każdej rośliny wprowadzano po 6 samic przędziorka chmielowca i pozostawiano je na 3 dni, aby złożyły jaja. Po tym czasie usuwano samice, określano liczbę złożonych jaj i pozostawiano ich około 200 na każdym liściu. Następnie wprowadzano 1 osobnika A. swirskii na każdy badany liść. Rejestrowano liczbę zjedzonych przez drapieżcę jaj i wylęgłych w czasie trwania doświadczenia larw po 3 i 7 dniach żerowania drapieżcy.

\section{Opracowanie statystyczne wyników}

Użyto program STATGRAPHICS Plus. Przeprowadzono jednoczynnikową analizę wariancji ANOVA. Zastosowano test Fishera na poziomie istotności 0,05.

\section{Wyniki i dyskusja / Results and discussion}

$\mathrm{Na}$ rysunku 1. przedstawiono wyniki I doświadczenia szklarniowego ilustrujące liczebność populacji $T$. urticae po 4 tygodniach rozwoju szkodnika na roślinach traktowanych i nietraktowanych biostymulatorami, tj. w momencie introdukcji A. swirskii oraz po 2 tygodniach działalności drapieżcy.

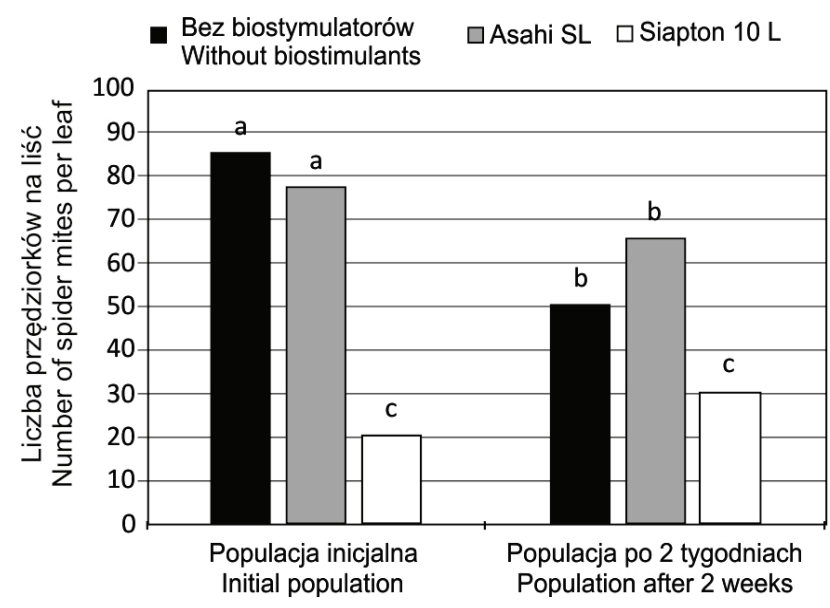

Rys. 1. Populacja Tetranychus urticae przed i po wprowadzeniu drapieżcy na rośliny ogórka. Różne litery nad słupkami oznaczają różnice istotne statystycznie

Fig. 1. The population of Tetranychus urticae before and after introduction of predator on cucumber plants. Different letters above the bars indicate statistically significant differences

W momencie wprowadzania drapieżcy populacja T. urticae była znacznie mniej liczna na roślinach traktowanych preparatem Siapton $10 \mathrm{~L}$ w porównaniu z innymi wariantami doświadczalnymi. Różnice były istotne statystycznie $\left(\mathrm{F}_{2 / 39}=7,22 ; \mathrm{p}=0,0072\right)$. Preparat ten wpływał wyraźnie niekorzystnie na rozwój populacji szkodnika, co obserwowano już we wcześniejszych badaniach (Tom- czyk i Rudzińska 2011). Wykazano, że biostymulatory, w tym Asahi SL i Siapton 10 L, mogą zmieniać chemiczny skład roślin, a także aktywność niektórych enzymów, co podnosi często poziom odporności roślin na stresy abiotyczne i biotyczne (Gawrońska i Przybysz 2011). Zmiany stężenia cukrów i białek oraz zwiększenie zawartości metabolitów wtórnych w tkankach roślin żywicielskich przędziorków wpływają na rozwój populacji tych roztoczy (Tomczyk 1989). Wykazano także zależność między chemicznym składem rośliny a zachowaniem drapieżcy $w$ stosunku do żerującego na tej roślinie szkodnika (Cortesero i wsp. 2000; Buitenhuis i wsp. 2014).

Wprowadzenie drapieżcy na rośliny ogórka skutecznie obniżyło możliwość rozwoju populacji przędziorka chmielowca. Po dwóch tygodniach od introdukcji A. swirskii liczba stadiów ruchomych tego szkodnika na liściach roślin opryskiwanych wodą i preparatem Asahi SL była niższa od 15 do $40 \% \mathrm{w}$ porównaniu $\mathrm{z}$ populacją inicjalną, mimo korzystnych warunków dla rozwoju szkodnika panujących w tym czasie w szklarni. Świadczy to o skuteczności A. swirskii w zwalczaniu $T$. urticae, zgodnie z wynikami uzyskanymi przez innych autorów (van Houten i wsp. 2007). Jedynie w przypadku zastosowania preparatu Siapton $10 \mathrm{~L}$ nie zaobserwowano obniżenia wyjściowej liczebności szkodnika w wyniku działalności drapieżcy, a nawet pewną tendencję do wzrostu jego zagęszczenia na liściach. Oznacza to niższą efektywność $A$. swirskii na liściach roślin traktowanych tym biostymulatorem. Zastosowanie preparatu Siapton $10 \mathrm{~L} \mathrm{w}$ uprawie ogórka nie sprzyjało także namnażaniu się drapieżcy (rys. 2). Populacja A. swirskii po 2 tygodniach rozwoju na roślinach traktowanych preparatem Siapton $10 \mathrm{~L}$ była istotnie niższa niż na roślinach traktowanych wodą i preparatem Asahi SL.

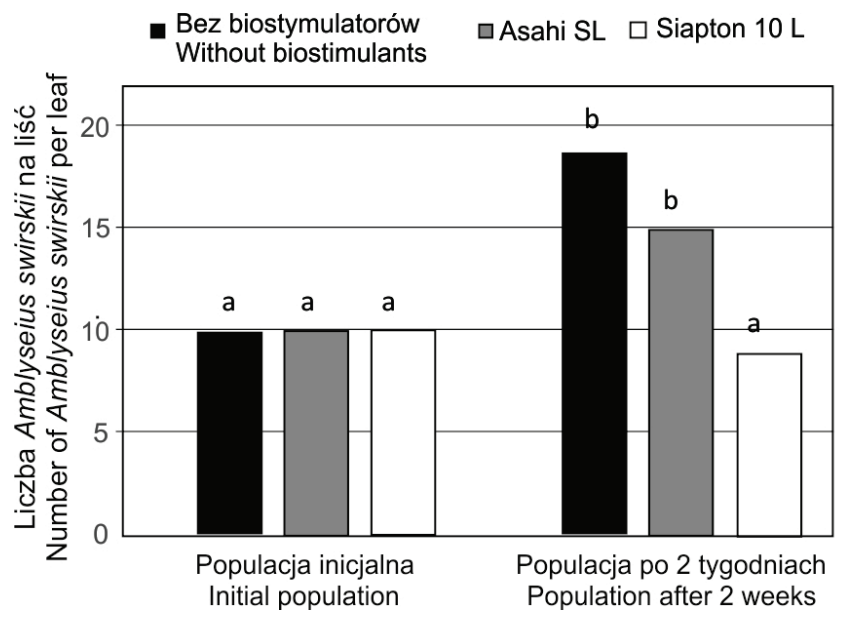

Rys. 2. Populacja Amblyseius swirskii przed i po wprowadzeniu drapieżcy na rośliny ogórka. Różne litery nad słupkami oznaczają różnice istotne statystycznie

Fig. 2. The population of Amblyseius swirskii before and after introduction of predator on cucumber plants. The different letters above the bars indicate the statistically significant differences

Rysunek 3. przedstawia wyniki II doświadczenia szklarniowego ilustrujące zmiany liczebności drapieżcy po 
3 tygodniach od momentu jego wprowadzenia na liście roślin z wysoką liczebnością populacji szkodnika, przekraczającą 200 osobników na liść.

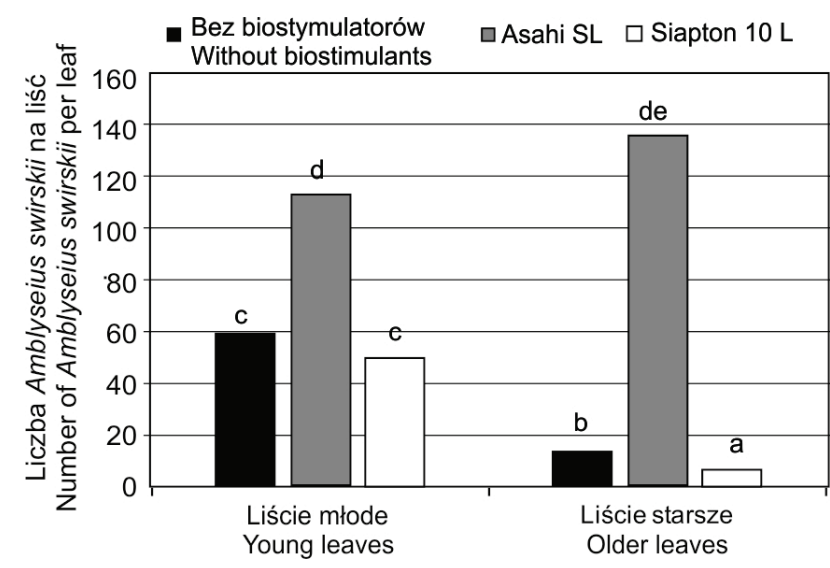

Rys. 3. Liczebność populacji Amblyseius swirskii po 3 tygodniach od introdukcji na silnie porażone przez Tetranychus urticae liście ogórka. Różne litery nad słupkami oznaczają statystycznie istotne różnice

Fig. 3. Population of Amblyseius swirskii 3 weeks after it's introduction on strongly infested by Tetranychus urticae leaves of cucumber. Different letters above the bars indicate statistically significant differences

Wyjątkowo wysoką liczebnie populację drapieżcy (prawie 140 osobników/liść na liściach starszych i ponad 110 osobników/liść na liściach wierzchołkowych) stwierdzono na roślinach traktowanych preparatem Asahi SL w porównaniu do kilkakrotnie mniejszej liczby drapieżcy na starszych liściach i ponad 2-krotnie mniejszej na młodych liściach roślin traktowanych wodą i preparatem Siapton 10 L. Najmniejszą liczbę drapieżcy stwierdzono na roślinach traktowanych preparatem Siapton $10 \mathrm{~L}$. Różnice były istotne statystycznie $\left(\mathrm{F}_{2 / 27}=9,24 ; \mathrm{p}=0,0009\right)$.

Uzyskane wyniki wskazują na wysoką atrakcyjność dla A. swirskii roślin uszkodzonych przez przędziorki, traktowanych preparatem Asahi SL. Wydaje się prawdopodobne, że przyczyną tego zjawiska mogą być specyficzne lotne substancje wydzielane przez uszkodzone liście tych roślin. Z badań Dicke i wsp. (1999) wynika, że uszkodzone przez szkodniki rośliny wydzielają lotne substancje, głównie terpenoidy i pochodne heksanu, które informują drapieżcę o obecności szkodnika i zwiększają jego aktywność. Autorzy zaobserwowali, że potraktowanie roślin wybranymi induktorami odporności, takimi jak kwas jasmonowy stymuluje wydzielanie lotnych substancji z uszkodzonych liści. Ilość i jakość wydzielanych substancji przez uszkodzone rośliny zależy od gatunku czy odmiany rośliny, od jej stanu fizjologicznego, a nawet od wieku uszkadzanych liści (Cortesero i wsp. 2000; Buitenhuis i wsp. 2014).

Badania laboratoryjne wykazały, że A. swirskii wprowadzony na liście ogórka, na których wcześniej złożyły jaja samice przędziorka chmielowca zjadał zarówno jaja, jak i rozwijające się $\mathrm{z}$ nich młode stadia rozwojowe (rys. 4). Największe zainteresowanie szkodnikiem drapieżca wykazywał na roślinach traktowanych preparatem
Asahi SL. W ciągu 7 dni $A$. swirskii zjadał na liściach tych roślin prawie dwukrotnie większą liczbę jaj i larw przędziorka chmielowca niż na liściach roślin kontrolnych i traktowanych preparatem Siapton 10 L. Różnice były istotne statystycznie $\left(\mathrm{F}_{2 / 33}=6,46 ; \mathrm{p}=0,012\right)$. Większa konsumpcja thumaczy intensywniejszy rozwój populacji drapieżcy na roślinach opryskiwanych preparatem Asahi SL.

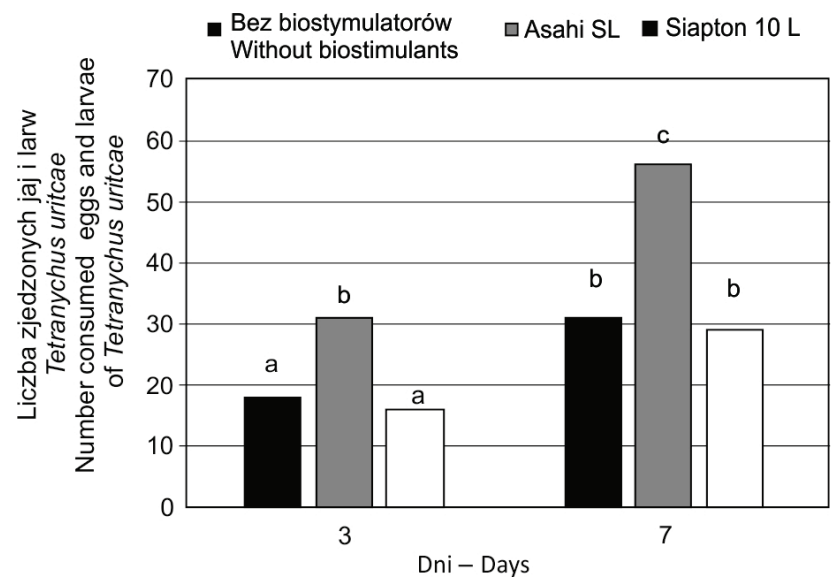

Rys. 4. Liczba jaj i młodych larw Tetranychus urticae zjedzonych przez Amblyseius swirskii na liściach roślin ogórka. Różne litery nad słupkami oznaczają różnice istotne statystycznie

Fig. 4. Number of eggs and young larvae of Tetranychus urticae consumed by Amblyseius swirskii on the leaves of cucumber plants. Different letters above the bars indicate statistically significant differences

Otrzymane wyniki wykazały, że wprowadzenie biostymulatorów do uprawy ogórka szklarniowego może wpływać zarówno na rozwój populacji szkodnika, jak i efektywność drapieżcy.

\section{Wnioski / Conclusions}

1. Populacja T. urticae rozwija się wolniej na roślinach ogórka traktowanych preparatem Siapton $10 \mathrm{~L}$ w porównaniu $\mathrm{z}$ innymi wariantami doświadczalnymi. Preparat ten wpływa wyraźnie niekorzystnie na rozwój populacji szkodnika.

2. Nie obserwuje się obniżenia liczebności $T$. urticae w wyniku działalności drapieżcy na liściach roślin ogórka potraktowanych preparatem Siapton $10 \mathrm{~L}$.

3. Zastosowanie preparatu Siapton 10 L w uprawie ogórka szklarniowego nie sprzyja namnażaniu się drapieżnego roztocza $A$. swirski, wprowadzonego w celu zwalczania przędziorka chmielowca.

4. Silnie uszkodzone rośliny przez przędziorka chmielowca, traktowane preparatem Asahi SL, stwarzają wyjątkowo korzystne warunki do rozwoju populacji A. swirskii.

5. Największe zainteresowanie szkodnikiem drapieżca wykazuje na roślinach traktowanych biostymulatorem Asahi SL. 


\section{Literatura / References}

Buitenhuis R., Shipp L., Scott-Dupree C., Brommit A., Lee W. 2014. Host plant effects on the behaviour and performance of Amblyseius swirskii (Acari: Phytoseiidae). Experimental and Applied Entomology 62 (2): 171-180.

Cortesero A.M., Stapel J.O., Lewis W.J. 2000. Understanding and manipulating plant attributes to enhance biological control. Biological Control 17: 35-47.

Dicke M., Gols R., Ludeking D., Posthumus M.A. 1999. Jasmonic acid and herbivory differentially induce carnivore-attracting plant volatiles in Lima bean plants. Journal of Chemical Ecology 25: 1907-1922.

Fiedler Ż. 2010. Wzajemne oddziaływanie Amblyseius cucumeris (Oudemas) i Amblyseius swirskii (Athias-Henriot) w ograniczaniu wciornastka zachodniego Frankliniella occidentalis (Pergande). [Interaction between Amblyseius cucumeris (Oudemas) and Amblyseius swirskii (Athias-Henriot) populations in control of western flower thrips - Frankliniella occidentalis (Pergande)]. Progress in Plant Protection/Postępy w Ochronie Roślin 50 (3): 1467-1470.

Gawrońska H., Przybysz A. 2011. Biostymulatory: mechanizmy działania i przykłady zastosowań. s. 7-13. W: Materiały Konferencyjne „Targi Sadownictwa i Warzywnictwa”. Agrosimex Sp. z o.o., Warszawa, 5-6.01.2011, 70 ss.

Górski R. 2008. Przydatność drapieżnego roztocza Amblyseius swirskii (Athias-Henriot) w biologicznym zwalczaniu mączlika szklarniowego (Trialeurodes vaporariorum Westwood) w uprawie gerbery. [Usefulness of predatory mite Amblyseius swirskii (Athias-Henriot) in biological control of greenhouse whitefly (Trialeurodes vaporariorum Westwood) in gerbera crop]. Progress in Plant Protection/Postępy w Ochronie Roślin 48 (4): 1291-1293.

Heintz K.M., van Driesche R.G., Parella M.P. 2004. Biocontrol in Protected Culture. Chicago Review Press, 560 pp.

Onzo A., Hanna R., Sabelis M.W. 2012. The predatory mite Typhlodromalus aripo prefers green mite induced plant odours from pubescent cassava varieties. Experimental and Applied Acarology 58 (4): 359-370.

Tomczyk A. 1989. Physiological and biochemical responses of different host plants to infestation by spider mites (Acarina: Tetranychidae). Rozprawy Naukowe i Monografie. Wydawnictwa SGGW AR, Warszawa, 112 ss.

Tomczyk A., Rudzińska D. 2011. Wpływ wybranych biostymulatorów roślin na szkodliwość przędziorka chmielowca (Tetranychus urticae Koch) dla ogórka szklarniowego. [Influence of selected biostimulators on harmfulness of two-spotted spider mite (Tetranychus urticae Koch) for glasshouse cucumber]. Progress in Plant Protection/Postępy w Ochronie Roślin 51 (1): 508-512.

van Houten Y.M., Hoogerbrugge H., Bolckmans K.J.F. 2007. Spider mite control by four phytoseiid species with different degrees of polyphagy. IOBC/WPRS Bulletin 30 (5): 123-127. 